\title{
Application of Life Cycle Assessment and similar methodologies in Asset Management: A multiple case study
}

\author{
Henrike Holwerda $^{\text {* }}$, Willem Haanstra ${ }^{\mathrm{a}}$, Jan Braaksma ${ }^{\mathrm{a}}$, Tom Coenen ${ }^{\mathrm{a}}$, João Santos ${ }^{\mathrm{a}}$ \\ ${ }^{a}$ University of Twente, Faculty of Engineering Technology, P.O. Box 217, 7500 AE Enschede, The Netherlands \\ * Corresponding author. Tel.: +31-053-489-7939. E-mail address: c.h.holwerda@utwente.nl
}

\begin{abstract}
Life Cycle Thinking (LCT) methodologies are increasingly adopted by Asset Management (AM) organizations to assess the sustainability impact of decisions in policy-making and strategic planning. Despite the adoption of these methodologies, in particular the Life Cycle Assessment (LCA), operationalization of the outcomes seems to lack attention in industry and research. This research aims to explore and better understand the application of LCT outcomes in AM decision-making. An exploratory literature review shows that the current LCT research strongly focuses on LCT as a method and methodological improvement to advance the adoption of the method, while the application of the LCT outcomes receives less attention. Based on the literature review a number of postulates were formulated and tested in an exploratory multiple case study at various AM organizations in the Netherlands, in which LCT has been adopted. Comparing these postulates with empirical findings indicates fundamental differences between LCT theory and practice, which seem to limit the application of the LCT outcomes. The research reveals that more attention is needed on the assistance in the operationalization of LCT outcomes. Furthermore, practitioners should consider redirecting some efforts from improving the analysis itself towards the operationalization of the LCT outcomes.
\end{abstract}

Keywords: Life Cycle Assessment; Life Cycle Thinking; Asset Management; decision-making

\section{Introduction}

Sustainable practice is becoming increasingly important for Asset Management (AM) organizations. Activities are increasingly directed towards sustainability and should take a life cycle perspective with the consideration of social, ecological, and economic impacts [1]. It is essential to have an understanding of the sustainability impacts over the asset life cycle from an organizational strategy perspective. Assessments are valuable as "they can be part of a (learning) process for improvement on integrated policy decisions within a network spectrum, enabling parties and coalitions to participate in an informed debate" [2].

Life Cycle Thinking (LCT) is a holistic life-cycle perspective that is adopted by many assessment methodologies. Life Cycle Assessment (LCA) is widely regarded as the de facto standard for evaluating the environmental impact associated with all stages in the life cycle of a product or system. It also forms the basis for many similar LCT methodologies, such as the Environmental Cost Indicator (ECI) and Business Case models for Sustainability framework (BCS) [3]. LCT methodologies can assist in multiple levels of (AM) decision-making, ranging from accounting to macro-level, such as strategic planning [4].

\subsection{Research gap, aim, and scope}

A large majority of existent literature focuses on LCT methodologies and case studies. At best, assumptions are made - implicitly or explicitly about the adoption of LCT methodologies to support sustainable practice. However, empirical research on the practical application of LCT outcomes in decision-making is scarce.

Therefore, this research aims to explore to what extent LCT leads to sustainable policy and operation through cases at several AM organizations in various sectors. By exploring the full process of the adoption of LCT methodologies, from the initial idea to the eventual application of outcomes, we aim to gain insights into the relationship between the adoption of LCT methodologies and its impact in decision-making processes towards sustainability.

\section{Methodology}

Since there is no idea yet on the factors that affect the application of LCT methodologies and their relationship, this research aims to explore potential 
concepts. For this exploration, we adopt an approach that is similar to that of Veldman et al. [5], Braaksma et al. [6], and Haanstra and Braaksma [7], by translating commonly accepted assumptions from literature into postulates. The postulates are structured according to a well-established framework in the field of AM. These postulates are used in multiple case studies because case studies are considered an appropriate method to address 'why' and 'how' questions [8,9]. The measures that were taken to ensure validity and reliability are summarized in Table 1 [8].

Table 1. Ensuring validity and reliability of the case study

\begin{tabular}{ll}
\hline Criterion & Implementation \\
\hline $\begin{array}{l}\text { Construct } \\
\text { validity }\end{array}$ & Validation of results by interviewees \\
$\begin{array}{l}\text { Internal } \\
\text { validity }\end{array}$ & $\begin{array}{l}\text { Research framework, pattern matching using } \\
\text { postulates, interview questions in accordance } \\
\text { with details of framework }\end{array}$ \\
External & $\begin{array}{l}\text { Selection of various levels of decision-making } \\
\text { at various AM organizations, author's expert } \\
\text { validity }\end{array}$ \\
opinions on uniqueness of case samples \\
Reliability & $\begin{array}{l}\text { Structured case study protocol, semi-structured } \\
\text { interview questions }\end{array}$ \\
\hline
\end{tabular}

\subsection{Case studies selection}

This research focuses on LCT-based assessments performed by AM organizations. To ensure alignment between the cases and the aim of this research, the following criteria were used for the selection of the LCT-based assessments:

- The assessment is performed or commissioned by an AM organization.

- The assessment aims to quantify aspects of sustainability from a life-cycle perspective.

- The assessment intends to be used in a subsequent decision-making process.

Three cases were selected from companies in various sectors. The LCT assessments were performed at various decision-making levels. The characteristics of the selected cases are shown in Table 2. Semi-structured interviews were conducted (one per case) with an employee that was involved throughout the assessment. Recordings were used to analyze the interviews and draw conclusions.

\section{Theoretical framework and postulates}

Because there is a strong belief that AM should be a key practice for delivering sustainability [10], guidance on the application of LCT outcomes in AM decision-making is sought in the international industry standard on Asset Management. According to that standard, the key requirements to an AM system are the context of the organization, leadership, planning, support, operation, performance evaluation, and improvement [11]. These requirements were translated into 6 postulates.

\subsection{Postulate 1: The assessment is aligned with the context in which it is performed.}

The intended application and reasons for carrying out the assessment should be stated in the goal and scope definition [12]. Therefore, it can be expected that there is a clear understanding of the context in which the assessment is performed. The scope of the assessment is expected to be determined [2], [13], [30], but also the context of the decision-making must be made clear beforehand [12]. Furthermore, the stakeholders' needs and expectations should be clear and aligned [11].

\subsection{Postulate 2: There is leadership throughout the assessment process.}

Leadership can contribute to raising awareness for the importance of the LCT assessment and thereby creating commitment [11]. The involvement of stakeholders is important [2], [14], [31] to share

Table 2. Characteristics of the case companies

\begin{tabular}{llll}
\hline & Company A & Company B & Company C \\
\hline Sector & Energy distribution network & Road and water infrastructure & Railway infrastructure \\
LCT experience & Low & Medium & High \\
Year of study & 2015 & 2019 & 2016 \\
Methodology & BCS* framework [3] & $\begin{array}{l}\text { ECI* (based on LCA) and MCI* } \\
\text { (based on MFA*) }\end{array}$ & Internal LCM* tool \\
Subject of study & Insight in sustainability of & Design of demountable circular bridge & Complementary solutions to mitigate \\
& distribution transformers & & effects of overhead lines damage \\
Decision level [4] & Level 1: accounting & Level 2: micro-level & Level 3: meso/macro-level \\
Performed by & Outsourced to university & Outsourced to consultancy firm & $\begin{array}{l}\text { Internally, complementary solution } \\
\text { assessed by partner }\end{array}$ \\
\hline
\end{tabular}

*BCS: Business Case models for Sustainability; ECI: Environmental Cost Indicator; MCI: Material Circularity Indicator; MFA: Material Flow Analysis; LCM: Life Cycle Management 
understanding, stimulate learning and successfully mediate various views on its implications for the assessment $[11,15,16]$. Also, a leader can make sure that the assessment process will stay aligned with the organization's policy and can manage the roles, responsibilities, and authorities of the stakeholders [11].

\subsection{Postulate 3: The assessment is performed according to a planning.}

An assessment is time-intensive and if the outcomes are to be applied in subsequent decisionmaking, they should become available to decisionmakers timely $[15,16]$. To do so, the assessment requires planning that is compatible with the planning of the decision-making. Objectives and the tools that will be used to achieve those objectives should be addressed in the planning [2]. Also, risks and opportunities to achieve the deadline in time should be included to avoid any delays [11].

\subsection{Postulate 4: Sufficient support is available throughout the assessment process.}

Sufficient support should be available to perform the assessment in order to deliver outcomes that are valuable for decision-making. It is therefore expected that the assessment is supported with sufficient resources (in the form of time, budget, and tools [2]), expertise (in the form of employees or outsourcing) [11]. Furthermore, relevant stakeholders are expected to be made aware of the assessment, in order to facilitate communication and sharing of information [11].

\subsection{Postulate 5: The outcomes of the assessment are evaluated in line with the goal.}

To interpret the outcomes, one should look beyond the aggregated impacts [12]. Uncertainties [9], [13], complexity, and variability [13] are important for decision-making, since these present potential future risks and opportunities that should be accounted for. Besides, synergies, conflicts, and trade-offs across the identified impacts should be evaluated [2] in order to formulate conclusions, limitations, and recommendations [12].

\subsection{Postulate 6: The outcomes of the assessment are communicated and used in line with the goal.}

The knowledge considered beforehand and generated and exchanged throughout the assessment is important for decision-making [18]. Communication in line with the goal of the assessment can therefore help to formulate corrective and preventive measures to mitigate risks and exploit opportunities, associated with the goal [2], [30]. The communicated outcomes and measures should advise decision-makers on which solution to select but also on the (continuous) improvement of the outcomes of a decision [11].

\section{Case study results}

The case study results are discussed per postulate in this section and summarized in Table 3.

\subsection{Postulate 1: The assessment is aligned with the context in which it is performed.}

Only limited support for this postulate was found. In all cases the goal and scope of the assessment were aligned with the context in which it was performed, such as stated by the project leader of Company B: "It just fitted within the objectives and developments that were going on at that moment". The policy advisor at Company A stated it as follows: "From the company, there was of course the intention to look at certain examples from practice and to analyse from theory what the variables are. Come up with proposals on how to introduce and establish [sustainability]."

Company $\mathrm{C}$ stated the following about the collaboration with their partner at the start of the assessment: "We wrote a report about the joint problem context and which part of the scope was to our partner to solve and which part to us. [...] There was a good collaboration between both parties." But he also stated that the expectations were really strong and hard to manage: "People just assume that the project will be continued" no matter the outcomes of the assessment. Company A recognized the difficulty in aligning the stakeholders' needs and expectations with the goal: "Everybody tries to make their own translation of sustainability. That is their own interpretation yet." This lack of alignment with needs and expectations is the reason why this postulate is only supported limitedly.

\subsection{Postulate 2: There is leadership throughout the assessment process.}

The extent to which this postulate was supported varied between the case studies. In all cases the roles and responsibilities were clear, but alignment with the policy at that moment and alignment between stakeholders was not managed well at Company A: "You need people that initiate things like a pioneer and that should be supported by higher management. As soon as that is not the case, it becomes really difficult to make changes." The maintenance specialist from Company C also acknowledged the lack of leadership: "I, but also the engineer, doubted if [the solution] was such a good 
idea." He confirmed that they waited for the assessment's outcomes to confirm their doubts, rather than managing it from the beginning.

At Company B, however, leadership was present and the alignment between stakeholders well managed: "With several colleagues [...] we adjusted what the starting points would be for this assessment. [...]. There are many knobs to turn. [...]And you noticed that there was much discussion about that. What is the actual valuation? Do we dare to trust on that and draw conclusions from it yet?" So, the support for this postulate varies between the case studies.

\subsection{Postulate 3: The assessment is performed according to a planning.}

The extent to which this postulate was supported varied between the case companies. Company B linked the deadline to the planning of a related project: "There was a clear deadline to the period after which we want to have the outcomes of that LCA. We made that clear from the beginning when we commissioned that project."

On the contrary, the maintenance specialist of Company $\mathrm{C}$ stated the following: "There was not a very tight deadline, not like Friday before noon, or something like that." But when asking about the decision-makers, he answered: "It was asked regularly what the current situation was. At a given moment, it should not have lasted much longer." The policy advisor at Company A stressed the risks of not having a clear deadline: "We do it all next to our normal activities. [...] And then you often see that topics that are affecting the operation less are postponed more easily." Despite the lack of planning, there were no substantial delays.

\subsection{Postulate 4: Sufficient support is available throughout the assessment process.}

Only limited support for this postulate was found. On the one hand, resources, willingness to cooperate and expertise were available sufficiently in all case studies. The project leader at Company B stated it as follows: "We indeed had the budget for it. That was partially because there is knowledge in our organization about how much such an assessment should cost." Company A described the willingness to cooperate as follows: "As soon as you support [sustainability as a theme], you automatically free up more time to cooperate." The maintenance specialist at Company C stated the following about the expertise: "That [support] was available and I always received good cooperation. [...] It is a lot of information to cough up, but there were really a few people that were busy with it very seriously and uncovered it all."
Both Company A and B relied on their partners for support, although they recognize the difficulty of collecting all information. As the project leader of Company B stated: "It was quite difficult for [our partner] to obtain sufficient basic information [about future innovations] from the producers for example because that were often Environmental Product Declarations that were not registered yet." This postulate is only limitedly supported since not all information was always available.

4.5. Postulate 5: The outcomes of the assessment are evaluated in line with the goal.

This postulate was widely confirmed during the case research. All three case companies seemed to evaluate the outcomes of the assessment critically and iterated the assessment process if necessary. The project leader of Company B for example stated the following: "Our colleagues have read along very critically" and spoke about "reviewing the outcomes against other aspects that were important for us in the consideration".

The maintenance specialist at Company $\mathrm{C}$ stated, however, that the consequences of poorly managed expectations came to light during the evaluation: "Our doubts were reflected in the outcomes and that resulted in dissatisfaction of the decision-maker because he thought it was a nice project that should be implemented. [...] He was somewhat indignant about it.". He further elaborated on that: "He believed that the valuation of the outage was not high enough. [...] That actually was the valuation like we always define it in our methodology. The decision-maker never immersed himself in it before." Nevertheless, this postulate was confirmed by all case studies.

\subsection{Postulate 6: The outcomes of the assessment are communicated and used in line with the goal.}

The extent to which this postulate was supported varied between the case studies. Communication to decision-makers did take place, even though it was challenging sometimes. The maintenance specialist of Company C stated: "A project is like some sort of child. Nobody wants to leave it behind [...] and often it is very difficult to convince people that it is not a good idea." The policy advisor at Company A stated that the outcomes should be communicated to and used by each employee differently: "To people in the operation, you need to precook things completely: this is what you should do. [...] To higher management, you need to be able to motivate it: why are we going in a certain direction?"

The outcomes of the assessment were used at Company B in a follow-up project: "You see that stakeholders are aware of the lessons that we 
learned from the LCA. You also see that we, as the initiator of the project actively steer on those." The policy advisor from Company A recognized this increased awareness and stated: "[Sustainability] is established in the organization more professionally. No one can ignore it any longer. [...] Only, it takes a lot of time to implement it well and to take it into our daily thinking." The solution of Company $\mathrm{C}$ was not placed after all, and their partner's solution was only implemented partly. So the support for this postulate varies largely between the case studies.

\begin{tabular}{|c|c|}
\hline Postulate & Results \\
\hline $\begin{array}{l}\text { 1. The assessment is aligned with } \\
\text { the context in which it is performed. }\end{array}$ & $\begin{array}{l}\text { Not all elements of } \\
\text { postulate supported }\end{array}$ \\
\hline $\begin{array}{l}\text { 2. A leader is managing alignment } \\
\text { during the assessment process. }\end{array}$ & $\begin{array}{l}\text { Not supported by all } \\
\text { case studies }\end{array}$ \\
\hline $\begin{array}{l}\text { 3. The assessment is performed } \\
\text { according to a planning. }\end{array}$ & $\begin{array}{l}\text { Not supported by all } \\
\text { case studies }\end{array}$ \\
\hline $\begin{array}{l}\text { 4. Sufficient support is available for } \\
\text { the assessment process. }\end{array}$ & $\begin{array}{l}\text { Not all elements of } \\
\text { postulate supported }\end{array}$ \\
\hline $\begin{array}{l}5 . \text { The outcomes of the assessment } \\
\text { are evaluated. }\end{array}$ & Supported \\
\hline $\begin{array}{l}6 . \text { The outcomes of the assessment } \\
\text { are communicated and used. }\end{array}$ & $\begin{array}{l}\text { Not supported by all } \\
\text { case studies }\end{array}$ \\
\hline
\end{tabular}

\section{Discussion}

In the case studies analyzed, the assessment was not always well aligned with the context in which it was performed (postulate 1). If the goal of the assessment is not embedded well into daily practice, it might be difficult to substantially impact daily practice with the outcomes. Literature describes this as a lack of a perceived need for the assessment [19].

Understanding the needs and expectations of stakeholders appeared to be difficult. If the lack of alignment between expectations and needs (originating from the first postulate) is not well managed (under the second postulate), it appeared to have consequences for the rest of the assessment process. In literature, the relevance of early involvement of stakeholders and timely access for decision-makers is stressed [13], [15,16]. Good leadership is therefore crucial (postulate 2).

In literature, an incompatible time-frame between the assessment and the subsequent decision-making (postulate 3 ) is named as a reason for the lack of application of outcomes [20]. However, the lack of planning did not seem to substantially impact the application of outcomes. This can potentially be explained by the fact that there were no substantial delays in the case studies analyzed.

The same seems to apply to the amount of support (postulate 4): The difficulty to collect information did not prevent the companies from applying the outcomes contrary to findings in literature [19,20].
According to literature, the evaluation of assessment outcomes (postulate 5) can be difficult because of the lack of interoperability with the outcomes of other processes [8], [12], [22], [29], [30]. Nevertheless, the case studies did not reveal any difficulties in this regard. However, the evaluation might be experienced as a difficult stage because the consequences of the lack of support for other postulates are revealed in this stage.

The communication of assessment outcomes appeared to be challenging, as acknowledged by $[18,19,24]$. Literature also documents a lack of trust in the outcomes $[14,22]$, but decision-makers had sufficient trust in the methodology and outcomes. Valuations of impacts were, however, questioned in some cases.

The use of the assessment outcomes (postulate 6) was mostly dependent on the context (postulate 1) and leadership (postulate 2). Using outcomes that are not in line with the expectations appeared to be difficult. Managing the alignment, in the beginning, might help this aspect. More generally, it is hard to sustain the impact in the long term and to use the outcomes for continuous improvement.

\section{Conclusion}

This research aimed to explore to what extent LCT leads to sustainable policy and operation. Implicit and explicit assumptions about its practical use have been explored against current practice in AM organizations. Fundamental differences between LCT theory and practice were indicated, which seem to limit the application of LCT outcomes in AM decision-making. The research showed that a potential lack of adoption of LCT methodologies in AM decision-making cannot be fully explained by methodological flaws, as many scholars attempt to do, but also by organizational aspects of the LCT assessment, like context, leadership, and support. This research indicates the need for procedures that facilitate the application of LCT outcomes in AM decision-making and the need for assistance in the operationalization of sustainability.

This research has some limitations and therefore, future research on this topic is recommended. The amount of available information was limited because of retrospective case studies. It could be worthwhile to study LCT processes prospectively to gain a deeper and wider understanding of factors that affect the application of the outcomes. Next, only a first step is made in understanding the application of LCT methodologies in AM decision-making, because of the exploratory character of this research. To make firm statements about this topic, follow-up research could include more case studies in a wider variety of contexts, multiple sources of information, 
and more in-depth questions. Nevertheless, this research provided a rich contextual insight into realworld applications of LCT methodologies and their pragmatic considerations. Thereby this research revealed some useful points of departure to further advance the field of sustainable Asset Management.

\section{Acknowledgments}

The authors wish to sincerely thank the three case study companies who have participated in this research. This research was co-funded by Liander N.V.

\section{References}

[1] Peças P, Götze U, Henriques E, Ribeiro I, Schmidt A, Symmank C. Life Cycle Engineering - Taxonomy and Stateof-the-Art. Procedia CIRP, vol. 48, Elsevier B.V.; 2016, p. 73-8. https://doi.org/10.1016/j.procir.2016.04.085.

[2] OECD. Guidance on Sustainability Impact Assessment. Guid Sustain Impact Assess 2010. https://doi.org/10.1787/9789264086913-en.

[3] Korse M, Ruitenburg RJ, Toxopeus ME, Braaksma AJJ. Embedding the Circular Economy in Investment Decisionmaking for Capital Assets - A Business Case Framework. Procedia CIRP 2016;48:425-30. https://doi.org/10.1016/j.procir.2016.04.087.

[4] Sustainability ECJRCI for E and. International Reference Life Cycle Data System (ILCD) Handbook - General guide for Life Cycle Assessment - Detailed guidance. 2010. https://doi.org/10.2788/38479.

[5] Veldman J, Klingenberg W, Wortmann H. Managing condition-based maintenance technology: A multiple case study in the process industry. J Qual Maint Eng 2011;17:4062. https://doi.org/10.1108/13552511111116240.

[6] Braaksma AJJ, Klingenberg W, Veldman J. Failure mode and effect analysis in asset maintenance: A multiple case study in the process industry. Int J Prod Res 2013;51:1055-71. https://doi.org/10.1080/00207543.2012.674648.

[7] Haanstra W, Braaksma AJJ. Life Cycle Costing in physical Asset Management: a multiple case study. 20th Int Work Semin Prod Econ 2018 2018:1-12.

[8] Yin RK. Case study research: design and methods LK https://ut.on.worldcat.org/oclc/782170820. 2nd [rev.]. Thousand Oaks, CA SE - XVII, 171 p. : Illustrations ; 23 Cm: Sage; 1994.

[9] Eisenhardt KM, Graebner ME. Theory Building from Cases : Opportunities and Challenges. Organ Res Methods 2007;50:25-32.

[10] Marlow DR, Beale DJ, Burn S. A pathway to a more sustainable water sector: Sustainability-based asset management. Water Sci Technol 2010;61:1245-55. https://doi.org/10.2166/wst.2010.043.

[11] ISO. ISO 55001 Asset management — Management systems - Requirements 2014.

[12] ISO. ISO 14040: Life cycle assessment - Principles and framework 2006

[13] Reale F, Cinelli M, Sala S. Towards a research agenda for the use of LCA in the impact assessment of policies. Int J Life Cycle Assess 2017;22:1477-81. https://doi.org/10.1007/s11367-017-1320-0.

[14] Guinée JB, Gorrée M, Heijungs R, Huppes G, Kleijn R, Wegener Sleeswijk A, et al. Life cycle assessment: An operational guide to the ISO standards. III Sci Backgr 2001:692.

[15] Kaatz E, Root DS, Bowen PA, Hill RC. Advancing key outcomes of sustainability building assessment. Build Res Inf 2006;34:308-20. https://doi.org/10.1080/09613210600724608.

[16] Bond A, Morrison-Saunders A, Pope J. Sustainability assessment: The state of the art. Impact Assess Proj Apprais 2012;30:53-62.

https://doi.org/10.1080/14615517.2012.661974.

[17] Cowell SJ, Fairman R, Lofstedt RE. Use of risk assessment and life cycle assessment in decision making: A common policy research agenda. Risk Anal 2002;22:879-94. https://doi.org/10.1111/1539-6924.00258.

[18] Thomson CS, El-Haram MA. Is the evolution of building sustainability assessment methods promoting the desired sharing of knowledge amongst project stakeholders? Constr Manag Econ 2019;37:433-60. https://doi.org/10.1080/01446193.2018.1537502.

[19] Clark G, De Leeuw B. How to improve adoption of LCA. Int J Life Cycle Assess 1999;4:184-7. https://doi.org/10.1007/BF02979492.

[20] Guérin-Schneider L, Tsanga-Tabi M, Roux P, Catel L, Biard Y. How to better include environmental assessment in public decision-making: Lessons from the use of an LCA-calculator for wastewater systems. J Clean Prod 2018;187:1057-68. https://doi.org/10.1016/j.jclepro.2018.03.168.

[21] Badurdeen F, Jawahir IS. Strategies for Value Creation Through Sustainable Manufacturing. Procedia Manuf 2017;8:20-7. https://doi.org/10.1016/j.promfg.2017.02.002.

[22] Galindro BM, Welling S, Bey N, Olsen SI, Soares SR, Ryding SO. Making use of life cycle assessment and environmental product declarations: A survey with practitioners. J Ind Ecol 2020:965-75. https://doi.org/10.1111/jiec.13007.

[23] Klöpffer W, Curran MA. Strengths and limitations of life cycle assessment. Backgr Futur Prospect Life Cycle Assess 2014:413. https://doi.org/10.1007/978-94-017-8697-3.

[24] Niekamp S, Bharadwaj UR, Sadhukhan J, Chryssanthopoulos MK. A multi-criteria decision support framework for sustainable asset management and challenges in its application. J Ind Prod Eng 2015;32:23-36. https://doi.org/10.1080/21681015.2014.1000401. 